Coordinator for Bibliographic and Digital Services

Haverford College

Haverford, PA

\title{
The ALCTS Networked Resources and Metadata Committee: Setting Course in a Sea of Change
}

\{A published version of this article appears in the 18:4 (2002) issue of OCLC Systems \& Services.\}

"Rapid changes in the means of information access occasioned by the emergence of the World Wide Web have spawned an upheaval in the means of describing and managing information resources. Metadata is a primary tool in this work, and an important link in the value chain of knowledge economics." - Erik Duval, et al.

\begin{abstract}
This article describes the work of the Networked Resources and Metadata Committee (NRMC), a committee within ALA's Association for Library Collections and Technical Services (ALCTS). The article discusses NRMC's history, initiatives, and program highlights, gleaned from an interview held with the present and past chairs of the committee. Numerous details about NRMC's role within the larger metadata community are shared, as are future directions for the committee.
\end{abstract}

\section{KEYWORDS}

Networked Resources and Metadata Committee; NRMC; Association for Library Collections and Technical Services; ALCTS; metadata; Ann Sandberg-Fox; William Fietzer; Mary S. Woodley

$\mathbf{R}$ eaders of this column are aware of some key organizations dedicated to furthering metadata development. The Open Archives Initiative, the World Wide Web Consortium, and of course, the Dublin Core Metadata Initiative, among countless others, work hard to enable progress in this maturing field. The Association for Library Collections and Technical Services (ALCTS), a division of the American Library Association, is one of these dedicated groups. During the 2002 Annual Conference held in Atlanta, I had a chance to speak with the current and past chairs of the Networked Resources and Metadata Committee (NRMC), the ALCTS divisional committee established to address metadata and related issues. The charge of the NRMC, available on its web site $<$ http://www.ala.org/alcts/organization/div/nrmc/nrmc.html >, reads:

Recognizing that a coherent view of networked information resources and metadata issues will benefit the activities of the division, its committees, and sections, the committee is charged

1. To provide a broad framework for information exchange on current research developments, tools, and activities affecting networked information resources and metadata; 
2. To coordinate and actively participate in the development and review of standards concerning networked resources and metadata in conjunction with the division's committees and sections, other units within ALA, and relevant outside agencies; and

3. To develop programs and to foster and sponsor education and training opportunities that contribute to and enhance an understanding of networked resources and metadata, their identity, content, technology, access, control, and use.

The NRMC achieves these goals through strong leadership and dedicated membership. The accomplishments of this group - nine appointed members (including the chair) and one intern -- are remarkable, given that the committee was born just seven years ago.

\section{SOME HISTORY}

The Networked Resources and Metadata Committee was established by the ALCTS Board of Directors in 1995 under the name Digital Resources Committee (DRC). Ann Sandberg-Fox chaired the committee from 1995-2000, and two other ALCTS members have since held the reigns: William Fietzer (2000-2001) and Mary S. Woodley

\section{NRMC Chairs}

1995-2000 Ann Sandberg-Fox, Cataloging Consultant \& Trainer 2000-2001 William Fietzer, University of Minnesota 2001-present Mary S. Woodley, California State University - Northridge (2001-present). The DRC was charged to "study and address issues regarding digital resources of all kinds," and to collaborate with the ALCTS Audio Visual Committee so as to not have overlapping scopes (Sandberg-Fox, 1996). As Ann notes, it was not easy convincing the ALCTS Board to create the DRC. "The committee had to fight to get its point across. In the end however, enough far-sighted people believed in us, and the committee was established."

The original charter for the Digital Resources Committee included a sunset clause stating that the committee would be disbanded after the 2000 annual conference. In 1998 however, the ALCTS Board asked the DRC to review its charge and modify its name to reflect the increase in metadata development occurring worldwide. In response to the Board's request, Ann formed a working group to review the DRC's charge and to consider a new name. In her report to the Board, Ann proposed the name "Networked Resources and Metadata Committee," citing the following reasons (SandbergFox, 1998):

The term 'networked resources' applies, as its name suggests, to those resources that are available via the Internet, World Wide Web, and other particular network environments. It is these materials that have been the focus of the DRC's program of work...In addition, the working group felt it important that 'metadata' be included in the proposed name change... [because of] its association with the networked resource environment where it was developed and has been implemented.

\section{WHAT'S IN A NAME?}

Reconstituting the Digital Resources Committee as the Networked Resources and Metadata Committee broadened the already ambitious mission of this group, yet also provided it the stability of a long-term contract within ALCTS. The sunset clause was abolished, and although the terrain that the NRMC faced was in many ways unknown, it set out to achieve the goals identified in its charge. 
Subcommittees were formed, including the Standards Subcommittee, which drafted the Standardized Handling of Digital Resources: An Annotated Bibliography, commonly referred to as the Standards Bibliography. "Cecelia Preston initiated the Standards Bibliography," says Ann. "It was her idea, and she worked extremely hard to develop it. Thanks to Bill and Mary, it continues to be a substantial contribution." As noted in the document, available on the NRMC's web site at <http://www.ala.org/alcts/publications/netresources/bib_main.html>, the Standards Bibliography "provide[s] a source of relevant information as it pertains to the issues facing ALCTS members as they address the collection, cataloging and provision of access to digital resources." This resource is updated frequently, and as Mary notes, "it will soon include items on metadata transport protocols, as well as descriptive, administrative, technical, and preservation metadata standards. The Standards Bibliography will be a more timely and relevant document." The work of mounting a lengthy and informative resource on the Web, although a common practice today, should not be overlooked. According to William, "the NRMC was one of the first committees to put materials up on the Web," with the Standards Bibliography first appearing on July 25, 1997, and meeting minutes appearing as early as January, 1996.

\section{THE STRUCTURE}

Although the Standards Subcommittee was productive, the NRMC was overloaded with subcommittees by the time William was appointed chair in 2000. He restructured the NRMC by exchanging subcommittees for task forces, and removed many of the formal liaison relationships with other committees, the exception being the liaison to the Cataloging and Classification Section's Committee on Cataloging: Description and Access (CC:DA). As William notes, "not having such a formal structure can be beneficial." Indeed, NRMC task forces have offered the committee the flexibility of convening to work on specific projects, and disbanding when these projects have been completed. Moreover, informal reports from NRMC members who attend other meetings serve the information needs of the group. As Mary notes, "as a divisional committee, we have the burden of making sure we coordinate with other committees within ALCTS."

\section{NRMC PROGRAMS}

If you are interested in metadata, and regularly attend ALA annual conferences, chances are you have attended an NRMC program. Some past programs include:

- $\quad$ "Intelligent Agents and the Digital Future," presented at the 1997 Annual Conference in San Francisco - this program's featured speaker was Clifford Lynch, then the Director of Library Automation at University of California

- $\quad$ "Security and the Digital Library: A Look at Authentication and Authorization Issues," presented in New Orleans in 1999 - Donald Waters, then of the Digital Library Federation, was part of a panel that explored issues of information integrity and user identity in an online environment

- $\quad$ "Fish, Fungus, and Photos: Librarians as Metadata Collaborators," the most recent program, presented in Atlanta in 2002 - a panel of speakers, including Bill Garrison of the Colorado Digital Library Project, presented viewpoints on metadata collaboration among libraries and non-library communities, such as museums and scientific institutions

The 2003 Annual Conference in Toronto will feature a two-day preconference metadata institute titled 
"Knowledge Without Boundaries" that will bring together an array of international presenters, including speakers from China, Canada, and Germany. In addition, a program will be held on the Open Archives Initiative Protocol for Metadata Harvesting that will feature some of the most highly-regarded practitioners of this innovative application.

\section{THE FUTURE OF THE NRMC}

"It's a big challenge keeping the committee a little ahead of the changes taking place" comments William. Nowhere is this more prevalent than in the Standards Bibliography, where maintenance of the acronym list is a job unto itself. "We're fortunate to have people who are not members of the NRMC interested and willing to help out," says Mary. "There's more work that the committee can do. We welcome them." As the committee looks towards the future, there is little time to rest. Mary has outlined ambitious goals for the year ahead. Continuing education of professionals, developing a clearinghouse for metadata, and outreach to the information community are just a few of the projects facing the NRMC. Much of this work will intersect with the Library of Congress' Action Plan, Bibliographic Control of Web Resources <http:/ / lcweb.loc.gov/catdir/bibcontrol/actionplan.html>, which resulted from the Bicentennial Conference on Bibliographic Control for the New Millennium held in 2000. ALCTS members are heavily involved in this initiative, and clearly there is an important role for the NRMC to play. "A lot has happened in a short period of time," notes Mary. And there's plenty on the way.

The author wishes to thank Ann Sandberg-Fox, William Fietzer, and Mary S. Woodley for their generous contributions to this article.

\section{REFERENCES}

Duval, E., Hodgins, W., Sutton, S. \& Weibel, S. (2002), "Metadata principles and practicalities," D-Lib Magazine, vol. 8, no. 4, Available: http://www.dlib.org/dlib/april02/weibel/04weibel.html (Accessed: 2002, April 16)

Sandberg-Fox, A. (1996) "ALCTS Digital Resources Committee." Personal correspondence provided by the author on June 16, 2002.

Sandberg-Fox, A. (1998) "Report of the Working Group on the DRC Proposed New name and Charge, June 17, 1998." Personal correspondence provided by the author on June 16, 2002. 